\title{
Understanding Facilities Management Practices to Improve Building Performance: The opportunity and challenge of the facilities management industry over the world
}

\author{
Astri Anindya Sari ${ }^{1, *}$ \\ ${ }^{1}$ Civil Engineering Department, Faculty of Engineering, State University of Malang, 65145 Malang, \\ Indonesia
}

\begin{abstract}
There is much evidence that green building which is initially believed to be the solution to solve the problems of climate change and energy crisis can not perform as expected. The fact that green buildings consumed more energy and emit more $\mathrm{CO}_{2}$ than expected during the actual operation is due to the problems of inefficiency in building operation and maintenance. Facilities management integrates the entire component of the built environment including people, process, place and technology to make sure that the built environment system works optimally. It offer important contributions to address the challenge of inefficiency in terms of building operation and maintenance thus make facilities management industry become one of the fastest growing industry in the world. By doing a literature review, this paper intends to understand more about the practices of facilities management in different part of the world. It is found that there is a stark contrast in the development of facilities management practices in the western countries as compared to that in the eastern countries. The industry of facilities management is relatively new and the research related to that field is still limited thus provide a huge opportunity to develop it in the future since the importance of this field is increasingly recognize.
\end{abstract}

\section{Introduction}

Nowadays climate change and energy crisis has become one of the world's biggest concerns. IEA, 2015 [1] stated that the building sector (including residential and commercial) consumes more than one-third of the world's total primary energy, those number is the highest compared to the energy consumption of other sector. In addition to that, IPPC (2014) [2] argue that population growth, migration to cities, and increasing levels of wealth and lifestyle changes globally have the potential to doubled or even tripled

\footnotetext{
* Corresponding author: astri.anindya.ft@um.ac.id
} 
the energy consumption and emission of the building sector by the mid century [3]. Green building is one of the strategies that are expected to solve that problem. Unfortunately there is much evidence to mention that many green buildings perform poorly and emit much more $\mathrm{CO}_{2}$ during actual operation [4]. Moreover, OECD/IEA (2013) [5] highlights that many green buildings which have been designed and built in a very efficient technologies and already been recognized with distinction awards such as LEED Platinum, also perform worst in terms of energy consumption. The energy consumption of those buildings are often much higher than expected [3]. Those facts reveals the opportunity of the building sector to reduce the energy consumption and to overcome the environmental issues caused by greenhouse gas emissions as well as mitigating the global climate change in the long term.

The gap between the predicted energy consumption and actual energy performance in green building may be caused by many things including the difference between the building design and the as-built building in terms of the technical workmanship and installations, choice of equipment and material during the construction stage, as well as the energy behavior of occupants, which has been disregarded in the energy simulation process [6]. The higher the technology applied to a building, the better occupant understanding on the way the building works and how to maintain it become more essential so that the building can perform as expected. Occupant is the one that use the building and operate it everyday that is why the success of an energy saving strategy in a building depends greatly on how the occupants understand and interact with the building's systems and technology $[7 ; 8 ; 9]$ In addition to occupant's better understanding in the operational phase, a good and proper maintenance system is also needed so that a building can be function optimally as expected in the design stage [10]. When the tensions between energy performance and maintenance practices are balanced, buildings operate efficiently. A proper maintenance is also important since it widely accepted that it costs up to five times more to operate and maintain a building than to construct it [11].

As stated before, the efficient building operation will result in the decreased of energy consumption, the maintenance costs as well as the reduced in the environmental emissions. Unfortunately, the efficiency in the building operation and maintenance is still a problem in most of the countries in the world that might be the main caused which makes green building can not perform as expected..

\section{Facility management, a way to energy and cost efficiency of the building}

Facilities management (FM) may offer important contributions to address the challenge of inefficiency in terms of building operation and maintenance. Facility managements is a form of asset management which integrate all of the component of the built environment including people, process, place and technology to make sure that the built environment system works optimally [12]. Considering that building or built environment is a complex system, so in terms of carrying its functions, facility management involves multidisciplinary knowledge including architecture, civil engineering, behavior, accounting, management, and so on.

In the past, facilities management is known as the field that serves only on the building operation and maintenance field. However, as the industry is growing rapidly the service of facilities management has become widespread nowadays. Teicholz [13] stated the 41 responsibilities set by the International Facilities Management Association (IFMA) which are grouped into eight categories covering real estate, planning, budgeting, space management, interior planning, interior installation, architecture or engineering services, and building maintenance and operations. 
As facility management comprises a very broad range of services, facilities management is considered to be a factor that has an important role to the success or failure of the effectiveness of building performance so that it can be optimally performs as its designed [14]. Implementing an efficient maintenance strategy is required to manage resources effectively and decrease the costs of repairs and replacements, in addition to reducing overall risk and equipment failure [15]. A good facility management system will ensure that every technology and facility equipped within a building is already well function and meet the standard. The facility management will also organize the people who are involve in the building operation and maintenance to make sure that the building can perform optimally and efficiently in terms of cost, operations, and maintenance as well as fulfill the client needs and features [16].

Research and practice of facilities management began to start in the USA in around 1950 's and followed by the Europe in around 1980's. The practices of facilities management have expanded to the countries of Asia and Africa since 1990's. The importance of its practices makes the industry of facilities management become one of the fastest growing industries in the world.

\section{Methodology}

This paper intends to provide more understanding on the practices of facilities management in both developed and developing countries by doing the literature review on the previous research published between the year of 2000-2017. At the initial process, we found 52 publications in the form of journal, proceeding, and Ph.D. thesis within the facilities management topic which is published between the year of 2000-2017. In the next process, we then excluded some publications that much focus on the management and education field and left 22 articles which are focus more on the architecture and civil engineering practices to be reviewed. The selected publications are mainly use observation, interview as well as questionnaire to the facilities management practitioner so that they can briefly describe the practices of facilities management in their country.

\section{Facilities management practices in the USA, Europe, and Australia}

FM services were first provided in the 1950's and 1960's in the USA and they were fully developed in the 1970s, while in the Europe facilities management practices had started to develop in 1980's [18]. The first country in Europe where facilities management practices started to grow is the United Kingdom. Back then, UK is considered as the most important facilities management market in Europe followed by Germany and France [17]. At present, the UK, the US, the Nordic Europe countries and the Netherlands are considered to lead the international developments in FM [18]. Italy is one of the European countries that facing a delay in the practices of facilities management compared to other countries. Such delay may be caused by the anomaly of the Italian economic structure, which is strongly biased towards small and medium enterprises. In particular, such anomaly does not fit either with an integrated facilities management approach or the traditional models based on in-house management. Nevertheless, there has been a rapid growth in the Italian market in the last decades as a caused to a diffused trend to outsource non-core activities and to a process of reorganization of the supply market [17]. Limited publication found related to the practices of facilities Management in Australia; however the development of facilities management practices within this country is shown by the presence of accreditation system that had been developed by The Facility Management Association of Australia (FMA Australia) in 2000. 
This accreditation system defines three levels of skill in practicing facilities management in organization.

Facilities management practices in USA and Europe is already performed widely by both the property developers and facilities management companies. In both the USA and Europe, operation and maintenance are included as the importance area in the facilities management practices; however the scope has become broader and includes the development of real estate and use of buildings in both the short and long term. The rapid development of facilities management practices in USA and Europe shows an increased awareness of the importance of the physical surroundings for the development of organizations [19]. The development of facilities management industry is followed by the increasing interest in the research related to the field of facilities management under the international organization of facilities management (IFMA).

Research in the field of facilities management has result in a standard for quality regulation in Europe which are the IS0 9000 Quality standards and EN 15221-3: 2008 Facility Management - Part 3 about guidance on how to achieve quality in facility management [20]. This standard is expected to be the basis of a common understanding related to the facilities management services thus emphasizes improvements of core businesses productivity and people's quality of life [21].

Some of the facilities management services in both Europe and USA are already left the traditional system (reactive maintenance) and move on into the integrative facilities management services which applying proactive maintenance [22]. The proactive maintenance in the integrative facilities management services will integrate the all of the building data from the design, construction, and the building operational phase to make the process of controlling and maintenance will be much easier to do. In the proactive maintenance, all of the system and technology will be controlled periodically so that the age of components, the decrease of the component function, and the damage of the component can be predicted and be repaired faster thus make the proactive maintenance to be more efficient in term of time and cost as well as to make the building perform more optimally [23].

There are some challenges in applying proactive maintenance that is faced by the facilities management practitioners in USA \& Europe. The first challenge is due to the difficult transitioning process from traditional reactive maintenance to proactive maintenance which involves not only the advancement of technology but also skill $[10 ; 19]$. The next challenge is the unorganized building data from the design and construction phase thus make the proactive maintenance process become difficult to do $[10 ; 24]$. The development of the newest Building Information Modeling (BIM) software which is being used in the design and construction phases will allow the knowledge sharing between facility management and design professionals. However, based on the research in the USA [24] and the Nordic Europe [19] found that there is a knowledge and technology gap between design and facility management professionals. In some cases, the facility management team may not present themselves during the design and construction stage, thus the designer do not know exactly on what kind of information that they should include in the BIM database that will be needed for the maintenance purpose later. Therefore a better practices and technologies are needed to carry such information with the understanding of facilities management's needs.

Other challenge in the growing service sector of facilities management the Europe is how to deal with service quality [20]. Even though FM practices in Europe and USA are already equipped with ISO standard but somehow there is still gaps between the facilities management practitioners and clients in terms of the services priority. Since quality is one of the most expected aspects by customers of almost all service products [25] so research 
about customer satisfaction and the post occupancy evaluation become the important thing to do.

\section{Facilities management practices in Asia \& Africa}

The practice of buildings facilities management in Asia \& Africa is still considered as a new comer in the industry if compared to those in Europe and USA [26]. In Asia, the facilities management practices has developed rapidly in the more developed countries of Japan, Hong Kong and Singapore, while in the developing countries of Asia such as Malaysia and Thailand, facilities management practices is still considered in the level of infancy. Hong Kong as the "door" to the Asia and the meeting point of western and Asian culture has become one of the leading country of facilities management practices in Asia. The facilities management practices in Hong Kong have began since 1994 under the local International Facilities Management Association [26]. This organization support and organize any research related to the field of facilities management in Hong Kong by organizing annual conference as a means of sharing knowledge between the researcher and facilities management practitioners in Hong Kong. In Singapore FM industry is already implementing the integrative facility management services with proactive maintenance despite the traditional one. By implementing the proactive maintenance building can perform more optimally as well as save more energy [3].

On the contrary, facilities management practice in the developing countries of Asia such as Thailand, Korea and Malaysia is still considered to be new and in the level of infancy. Some survey that held on Korea and Malaysia shows the low awareness of people in the importance of facilities management practice towards the better performance of a building and built environment [27].

In the developing countries of Asia such as Malaysia, the practices of facilities management is generally done by the outsourcing partner which is the international facilities management company, there is no local facilities management company found in Malaysia [16]. However, the development of facilities management practices and research in this country shows that there is a growing interest on this in Malaysia, thus give a positive insight to the future development of facilities management industry in this country.

Most of the practice of facility management in Malaysia at present is undertaken by real estate firms as the property consultant. This is due to the fact that buildings such as high rise office towers are managed by property consultants. The maintenance method that they use is mostly the traditional of reactive maintenance instead of the proactive one [26]. Reactive maintenance is a maintenance and repair method which is being done only if some damage is being found. This method of reactive maintenance and repairs are not efficient, since it cost three to four times more than the proactive maintenance for the same repair [23]. Unfortunately this method is chosen due to the poor record of data management since the design and construction phase that make the process of proactive maintenance difficult to do. Moreover, the poor data management is also result in the negative future planning of maintenance works and services management.

Min et al., [3]; Myeda, \& Pitt [27] stated that some other challenge the practice of FM in Malaysia and other Asian country are (1) the lack of the people understanding of the importance of providing a comprehensive FM services to achieve the desired building performance 2) lack of skill, technical knowledge and expertise on the building services and facility management field so the difficulty of handling various problems is often occur thus the need to design a flexible FM planning that can be applied. 3) Lack of the standard and guidelines in the FM services that can be used to measure the quality and performance of FM practices by company as well as to standardize the practice and implementation 4) the absence of specific FM organization to control and monitor the FM practiced by 
property management or consultants in Malaysia. 4) Lack of financial support since adoption of integrated FM requires high initial costs, unless the computerized programs can be developed locally in the market or funding support is provided, thus make Malaysia is still lagging behind in software development specific to FM. In addition to that, Kamaruzzaman and Zawawi [29] argue that public awareness of the role of FM is still low and attributed that to lack of an FM culture in Malaysia.

Nevertheless, the Government of Malaysia had taken some initiative to provide quality of public services in terms of setting rules and providing budget, yet the government has not yet implemented and adopted the facilities management in any organized way $[27 ; 28]$. The first facilities management organization in Malaysia (Malaysian Association of Facilities Management) was formed in 2001; however there are no remarkable steps that they have taken up to now to promote the FM profession locally. It can be concluded that FM practices is relatively new in Malaysia, it is unlikely that facility management will be widely practiced for some time in the Malaysian property sector until the property management industry fully matures.

\section{Discussion}

Applying integrated facilities management and the proactive maintenance is proven to be more effective and efficient in terms of time and cost if compared to the traditional reactive maintenance. However, applying integrated facilities management is still a challenge in both the developed and developing countries since it required not only a complicated way of transfer knowledge and technology but also a strong financial support. Moreover, different culture of eastern and western might be have different preference and challenge, so there might be different strategies which is more suitable and effective to be applied in certain culture. In order to address that problem, the future research within this area is suggested to do. Beside that, since the preferences gap between the facilities management practitioners and the clients concerning the service area priority is also a challenge faced by the management practices, future research related customer satisfaction and post occupancy evaluation is also in need to do.

\section{Conclusion}

There is a stark differences and slight similarity between the practice of facility management in the developed countries in USA and Europe as compared to the developing countries in Asia and Africa. The differences are concerning the quality of services, the number facilities management standards that exist, and the number of research published while the similarity is the lack of financial support that faced by the Asian countries as well as some European countries and the Australia and the challenge in applying integrated facilities management.

This field of facilities management is relatively new, yet the fast growing development of this industry over the last 25 years have proven that this field is getting increasingly recognized. On the other hand, many challenges that still faced by the facility management practitioners over the world offer many opportunity for researcher to help solving the problems that occur and filling the gaps of knowledge in this field.

\section{References}

1. U.S. Energy Information Administration, Off. Integr. Int. Energy Anal (2015) 
2. O. Lucon, D. Ürge-Vorsatz, A. Zain Ahmed, H. Akbari, P. Bertoldi, L.F. Cabeza, N. Eyre, A. Gadgil, L.D.D. Harvey, Y. Jiang, E. Liphoto, S. Mirasgedis, S. Murakami, J. Parikh, C. Pyke, and M.V. Vilariño, Clim. Chang. 2014 Mitig. Clim. Chang. Contrib. Work. Gr. III to Fifth Assess. Rep. Intergov. Panel Clim. Chang. (2014)

3. Z. Min, P. Morgenstern, and L. Marjanovic-Halburd, Int. J. Sustain. Built Environ. 5 197-209 (2016)

4. C. Turner and M. Frankel, New Build. Inst (2008)

5. Transition to Sustainable Buildings: Strategies and Opportunities to 2050 (2013)

6. K. Schakib-Ekbatan, F.Z. Çakici, M. Schweiker, and A. Wagner, Build. Environ. 84, 142-150 (2015)

7. O.T. Masoso and L.J. Grobler, Energy Build. 42(2), 173-177 (2010)

8. D. Yan, W. O'Brien, T. Hong, X. Feng, H. Burak Gunay, F. Tahmasebi, and A. Mahdavi, Energy Build. 107, 264-278 (2015)

9. T. Hong, D. Yan, S. D’Oca, and C. fei Chen, Build. Environ. 114, 518-530 (2017)

10. A. Lewis, A. Elmualim, and D. Riley. CIB 2010 World Congress Proceedings. Salford Quays, United Kingdom: The Lowry. (2010)

11. B. McAuley, A. V. Hore, and R. West, Proc. RICS Cobra 2013 (2013)

12. International Facility Management Association, Http://Www.Ifma.Org/About/What-IsFacility-Management (2009)

13. Teicholz, E. (2001). Facility Design and Management Handbook. USA, McGraw-Hill

14. S. Chotipanich, Facilities. 22, 13/14, 364- 72 (2004)

15. A. Chandrashekaran and B. Gopalakrishnan, J. Facil. Manag. 6(1), 52-68 (2008)

16. H. Hashim, A.A. Saleh, N. Kamarulzaman, and S.Z. Hashim, in Procedia Eng. 20, 284-290 (2011)

17. A. Ancarani and G. Capaldo, J. Purch. Supply Manag. 11, 232-241 (2005)

18. P.A. Jensen. (2012), "National FM research overviews", in: Jensen P.A. and Nielsen S.B. (eds.), Facilities Management Research in the Nordic countries. Past, present and future. Polyteknisk forlag:

19. P.A. Jensen, Archit. Eng. Des. Manag. 5(3), 124-135. (2009)

20. N. Lepkova and R. Uselis, in Procedia Eng. 57, 697-706. (2013)

21. T.B. Haugen and N.J. Klungseth, J. Facil. Manag. 15(3), 262-284. (2017)

22. V. Maliene, K. Alexander and N. Lepkova International Journal of Environment and Pollution. 35. 2/3/4, 171-184 (2008)

23. W. Shen, Q. Hao, H. Mak, J. Neelamkavil, H. Xie, J. Dickinson, R. Thomas, A. Pardasani, and H. Xue, Adv. Eng. Informatics. 24(2), 196-207 (2010)

24. R. Liu and R. R. A. Issa. Computing in Civil Engineering. 411-418 (2013)

25. W. Urban, Technol. Econ. Dev. Econ. 15(4), 631-645. (2009)

26. N. Elyna Myeda and M. Pitt, Facilities. 32 .490-508 (2014)

27. S.A.H. bin Syed Mustapa and K. Jusoff, J. Sustain. Dev. 1(2), 79 (2009)

28. S. Nizam Kamaruzzaman and E. Marinie Ahmad Zawawi, J. Facil. Manag. 8(1). 75-81 (2010) 